\title{
Front Matter: Volume 9167
}

, "Front Matter: Volume 9167," Proc. SPIE 9167, Spintronics VII, 916701 (10 September 2014); doi: 10.1117/12.2081207

SPIE Event: SPIE NanoScience + Engineering, 2014, San Diego, California, United SPIE. States 


\title{
PROCEEDINGS OF SPIE
}

\section{Spintronics VII}

\author{
Henri-Jean Drouhin \\ Jean-Eric Wegrowe \\ Manijeh Razeghi \\ Editors
}

17-21 August 2014

San Diego, California, United States

Sponsored and Published by

SPIE 
The papers included in this volume were part of the technical conference cited on the cover and title page. Papers were selected and subject to review by the editors and conference program committee. Some conference presentations may not be available for publication. The papers published in these proceedings reflect the work and thoughts of the authors and are published herein as submitted. The publisher is not responsible for the validity of the information or for any outcomes resulting from reliance thereon.

Please use the following format to cite material from this book:

Author(s), "Title of Paper," in Spintronics VII, edited by Henri-Jean Drouhin, Jean-Eric Wegrowe, Manijeh Razeghi, Proceedings of SPIE Vol. 9167 (SPIE, Bellingham, WA, 2014) Article CID Number.

ISSN: 0277-786X

ISBN: 9781628411942

Published by

SPIE

P.O. Box 10, Bellingham, Washington 98227-0010 USA

Telephone +1 3606763290 (Pacific Time) · Fax +1 3606471445

SPIE.org

Copyright (C) 2014, Society of Photo-Optical Instrumentation Engineers.

Copying of material in this book for internal or personal use, or for the internal or personal use of specific clients, beyond the fair use provisions granted by the U.S. Copyright Law is authorized by SPIE subject to payment of copying fees. The Transactional Reporting Service base fee for this volume is $\$ 18.00$ per article (or portion thereof), which should be paid directly to the Copyright Clearance Center (CCC), 222 Rosewood Drive, Danvers, MA 01923. Payment may also be made electronically through $\mathrm{CCC}$ Online at copyright.com. Other copying for republication, resale, advertising or promotion, or any form of systematic or multiple reproduction of any material in this book is prohibited except with permission in writing from the publisher. The CCC fee code is 0277-786X/14/\$18.00.

Printed in the United States of America.

Publication of record for individual papers is online in the SPIE Digital Library.

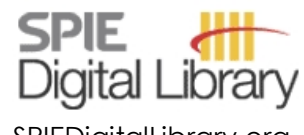

SPIEDigitalLibrary.org

Paper Numbering: Proceedings of SPIE follow an e-First publication model, with papers published first online and then in print and on CD-ROM. Papers are published as they are submitted and meet publication criteria. A unique, consistent, permanent citation identifier (CID) number is assigned to each article at the time of the first publication. Utilization of CIDs allows articles to be fully citable as soon as they are published online, and connects the same identifier to all online, print, and electronic versions of the publication. SPIE uses a six-digit CID article numbering system in which:

- The first four digits correspond to the SPIE volume number.

- The last two digits indicate publication order within the volume using a Base 36 numbering

system employing both numerals and letters. These two-number sets start with 00, 01, 02, 03, 04,

$05,06,07,08,09,0 A, 0 B \ldots$. OZ, followed by 10-1Z, 20-2Z, etc.

The CID Number appears on each page of the manuscript. The complete citation is used on the first page, and an abbreviated version on subsequent pages. Numbers in the index correspond to the last two digits of the six-digit CID Number. 


\title{
Contents
}

\author{
vii Authors \\ xi Conference Committee \\ $\mathrm{xV}$ Introduction
}

\section{SPIN LASER}

916703 Polarization dynamics in spin-polarized vertical-cavity surface-emitting lasers (Invited Paper) [9167-2]

\section{SPIN COHERENCE IN QUANTUM DOTS}

916705 Applications of femtosecond pulse engineering in the control of excitons in quantum dots (Invited Paper) [9167-4]

916707 Room-temperature initialization, dynamics, and measurement of coherent electron spins in strongly confined quantum dots (Invited Paper) [9167-6]

916708 Epitaxial growth of CaMnTe quantum dots directly on Si(111) (Invited Paper) [9167-7]

\section{OPTICAL PUMPING I}

916709 Determination of spin diffusion length in Germanium by optical and electrical spin injection (Invited Paper) [9167-8]

9167 OA Optical orientation of electron spins in GaAs L-valleys (Invited Paper) [9167-9]

9167 OC Spin-dependent transport as a consequence of Pauli blockade in a degenerate electron gas (Invited Paper) [9167-11]

\section{SPIN COHERENCE II}

9167 OD Spin-orbit interaction and spin coherence in narrow-gap semiconductor and semimetal wires (Invited Paper) [9167-12]

\section{SPIN PHOTONICS}

$9167 \mathrm{OH}$ Spin-resolved study of direct band-gap recombination in bulk Ge (Invited Paper) [9167-16]

$916701 \quad$ Photonic spin Hall effect for precision metrology (Invited Paper) [9167-17] 
9167 0J The charge-magnet paradoxes of classical electrodynamics (Invited Paper) [9167-18]

SPIN COHERENCE AND MAGNETIC POLARONS

9167 OK Individual cobalt and manganese ions in semiconductor quantum dots and photonic structures (Invited Paper) [9167-19]

$9167 \mathrm{OL}$ Conventional versus unconventional magnetic polarons: ZnMnTe/ZnSe and ZnTe/ZnMnSe quantum dots (Invited Paper) [9167-21]

\section{OPTICAL PUMPING II}

$91670 \mathrm{M}$ Direct observation of non-thermal influence in the process of photo-induced ferromagnetic resonance in (Ga,Mn)As (Invited Paper) [9167-22]

9167 ON Modeling optically pumped NMR and spin polarization in GaAs/AIGaAs quantum wells (Invited Paper) [9167-23]

916700 Experimental measurements of optically pumped NMR (OPNMR) and spin polarization in bulk GaAs and GaAs/AIGaAs quantum wells (Invited Paper) [9167-24]

MULTIFERROICS, HALF METALS, AND OXIDES

9167 OS Magneto-optical investigation of Fe/CoO/Fe(001) trilayers (Invited Paper) [9167-28]

9167 OT Static and dynamic magnetic property of MBE-grown Co2FeAl films (Invited Paper) [9167-29]

9167 OU Ultra-low-energy straintronics using multiferroic composites (Invited Paper) [9167-30]

\section{HELICAL ORDER AND ORGANICS}

916713 Direct observation of a highly spin-polarized organic spinterface at room temperature (Invited Paper) [9167-39]

\section{MAGNETOOPTICS AND LANDÉ FACTOR}

916718 Time resolved magneto-optical studies of InAsP ternary alloys (Invited Paper) [9167-44]

MAGNETIC RAM I

9167 1B Status and outlook of STT-MRAM development (Invited Paper) [9167-47]

iv 
$91671 \mathrm{H}$ Time resolved transport studies of magnetization reversal in orthogonal spin transfer magnetic tunnel junction devices (Invited Paper) [9167-53]

9167 1J High-performance computing based on spin-diode logic (Invited Paper) [9167-55]

SPIN CALORIC TRANSPORT I

$91671 \mathrm{M}$ Anomalous spin and charge Seebeck effect in a quantum well with spin orbit interaction (Invited Paper) [9167-58]

\section{SPIN CALORIC TRANSPORT II}

916710 Spin-Hall effects: from the two-channel model to Dyakonov-Perel equations (Invited Paper) [9167-60]

\section{SPIN-ORBIT COUPLING}

916721 Spin control and manipulation in (111) GaAs quantum wells (Invited Paper) [9167-73]

916723 Spin injection and spin-orbit coupling in low-dimensional semiconductor nanostructures (Invited Paper) [9167-75]

\section{SPIN PUMPING I}

916729 Spin pumping and inverse spin Hall effect in platinum and other $5 d$ metals: the essential role of spin-memory loss and spin-current discontinuities at interfaces (Invited Paper) [9167-81]

\section{ULTRAFAST OPTICAL CONTROL AND TOPOLOGICAL INSULATORS I}

$91672 \mathrm{C}$ Attempting nanolocalization of all-optical switching through nano-holes in an Al-mask (Invited Paper) [9167-84]

$91672 \mathrm{D}$ Ultrafast spin dynamics in metallic layers and strongly correlated oxides (Invited Paper) [9167-85]

$91672 \mathrm{E}$ Weak localization and weak anti-localization in topological insulators (Invited Paper) [9167-86]

SPIN PUMPING II

$91672 \mathrm{H} \quad$ Three-magnon splitting controlled by temperature (Invited Paper) [9167-89] 
$91672 \mathrm{~J}$ Dual-frequency ferromagnetic resonance to measure spin current coupling in multilayers (Invited Paper) [9167-91]

SPIN PUMPING AND SPIN NOISE

$91672 R \quad$ Spin noise spectroscopy in semiconductors: from a billion down to single spins (Invited Paper) [9167-99] 


\section{Author Index}

Numbers in the index correspond to the last two digits of the six-digit citation identifier (CID) article numbering system used in Proceedings of SPIE. The first four digits reflect the volume number. Base 36 numbering is employed for the last two digits and indicates the order of articles within the volume. Numbers start with 00, 01, 02, 03, 04, 05, 06, 07, 08, 09, OA, OB...0Z, followed by 10-1Z, 20-2Z, etc.

Adur, Rohan, 2J

Alouani, M., 13

Amand, Thierry, OA

Ando, Kazuya, $2 \mathrm{H}$

Arabski, J., 13

Attané, J.-P., 29

Balocchi, Andrea, OA

Barate, Philippe, OA

Barman, B., OL

Beaurepaire, E., 13

Bekaert, J., 1B

Berezovsky, Jesse, 07

Berski, F., 2R

Bertacco, Riccardo, 09, 13

Berti, G., OS

Bertoli, Stefano, 09

Bertran, F., 13

Bianchi, Massimiliano, 09

Biermann, K., 21

Borghs, G., OD

Boschini, Fabio, 2D

Boukari, S., 13

Bowen, M., 13

Bowers, C. R., ON

Brambilla, A., OS

Bringer, Andreas, 23

Brookes, N. B., 13

Bussetti, Gi., OS

Cadiz, F., OC

Calloni, A., OS

Cantoni, Matteo, 09, 0S, 13

Capps, Jeremy, $1 \mathrm{M}$

Carpene, Ettore, 2D

Carrère, Hélène, $0 \mathrm{~A}$

Cartwright, A. N., OL

Cerullo, Giulio, 09

Chaves-O'Flynn, Gabriel, $1 \mathrm{H}$

Chen, Shizhen, 0 l

Chou, W. C., OL

Ciccacci, F., OS

Coseman, S., $1 \mathrm{~B}$

Dahbashi, R., 2R

Dallera, Claudia, 2D

De Cesari, Sebastiano, $\mathrm{OH}$

Demarina, Natalia, 23

Deppe, Dennis G., 05

Deranlot, C., 29

Dilcher, Eric, 05

Djeghloul, F., 13
Drouhin, H.-J., 10

Du, Chunhui, 2J

Duò, L., OS

Dürr, H. A., 2C

Fan, W. C., OL

Ferreira, Sukarno O., 08

Finazzi, M., OS

Freisem, Sabine, 05

Friedman, Joseph S., $1 \mathrm{~J}$

Fumani, Ahmad K., 07

Gambarelli, S., 29

Gamouras, Angela, 05

George, J.-M., 29

Gerhardt, Nils C., 03

Gerster, Thomas, 23

Giorgioni, Anna, $\mathrm{OH}$

Graves, C. E., 2C

Grilli, Emanuele, $\mathrm{OH}$

Grützmacher, Detlev, 23

Guzzi, Mario, $\mathrm{OH}$

Hall, Kimberley C., 05

Hammel, P. Chris, 2J

Hardtdegen, Hilde, 23

Hayes, Sophia E., ON, 00

Hedayat, Hamoon, 2D

Heedt, Sebastian, 23

Heremans, J. J., OD

Hernández-Mínguez, A., 21

Hey, R., 21

Hoffmann, M. C., 2C

Hofmann, Martin R., 03

Höpfner, Henning, 03

Hübner, J., 2R

Huo, Yan, OT

Ibrahim, F., 13

Isella, Giovanni, $\mathrm{OH}$

Jaafar, A., 13

Jaffrès, $H_{\text {., }} 29$

Jamet, M., 29

Javaid, S., 13

Joly, L., 13

Kallaher, R. L., OD

Kappler, J.-P., 13

Kar, G. S., 1B

Kardasz, Bartek, $1 \mathrm{H}$

Kent, Andrew D., 1H

Kettemann, Stefan, 23

Khodaparast, G. A., 18

Kimel, A. V., 2C 
Kirilyuk, A., 2C

Kuhn, H., 2R

Kuhns, P. L., ON

Lacour, D., 10

Laczkowski, P., 29

Lage, Marielle H. M. B., 08

Le Fèvre, P., 13

Lindemann, Markus, 03

Liu, T.-M., 2C

Liu, Yachao, Ol

Lonnemann, J., 2R

LU, Hai-Zhou, 2E

Luo, Hailu, $\mathrm{Ol}$

Madon, B., 10

Magill, B. A., 18

Malachias, Angelo S., 08

Manolescu, Andrei, 1M

Mansuripur, Masud, OJ

Manuilov, Sergei A., 2J

Manzoni, Cristian, 09

Marangoni, Marco, 09

Marie, Xavier, OA

Marinescu, D. C., $1 \mathrm{M}$

Mathew, Reuble, 05

Matsuda, Takashi, OM

Matsuura, Saki, 2H

Mattana, R., 13

McCarthy, L. A., ON

McCombe, B. D., OL

McGill, S. A., ON, 18

Meeker, M. A., 18

Merrit, T. R., 18

Mertens, S., 1B

Min, T., 1B

Miyamachi, T., 13

Munekata, Hiro, OM

Murphy, J. R., OL

Nie, Shuaihua, OT

Nishibayashi, Kazuhiro, OM

Nishimura, K., 1B

Oestreich, M., 2R

Ohresser, P., 13

Okuyama, H., 1B

Oszwaldowski, R., OL

Pacuski, Wojciech, OK

Paget, D., OC

Palmstrøm, C. J., 18

Petrou, A., OL

Petukhov, A., OL

Pezzoli, Fabio, $\mathrm{OH}$

Picone, A., OS

Pientka, J. M., OL

Pinarbasi, Mustafa, $1 \mathrm{H}$

Puppin, Ezio, 2D

Qiao, Shuang, OT

Querlioz, Damien, 1 J

Radisic, D., 1B

Ramachandran, Ajan P., 05

Rasing, Th., 2C
Reid, A. H., 2C

Renucci, Pierre, OA

Reyes, A. R., ON

Reyren, N., 29

Rinaldi, Christian, 09, 13

Riva, M., OS

Rojas-Sánchez, J.-C., 29

Rowe, A. C. H., OC

Roy, Kuntal, OU

Rudolph, M., OD

Saha, Dipta, 0N, 00

Sahakian, Alan V., 1 J

Sanders, Gary D., ON, 00

Santos, M. B., OD

Santos, P. V., 21

Savero, W., 29

Savoini, M., 2C

Schäpers, Thomas, 23

Scheurer, F., 13

Schubert, Jürgen, 23

Scrace, T., OL

Seino, T., 1B

Sellers, I. R., OL

Seneor, P., 13

Sesti, Erika L., ON, 00

Shen, Shun-Qing, 2E

Shi Yang, Hong Yi, 05

Sladek, Kamil, 23

Sordan, Roman, 09

Souriau, L., 1B

Stanton, Christopher J., ON, 00

Stöhr, J., 2C

Swerts, J., 1B

Taleb-lbrahimi, A., 13

Tashiro, Takaharu, $2 \mathrm{H}$

Thakur, P., 13

Tokarski, J. T., III, ON

Tsai, Y., OL

Tsukamoto, A., 2C

Tsunekawa, K., 1B

Urbaszek, Bernhard, OA

Van Roy, W., OD

Vavassori, P., OS

Vila, L., 29

Wang, Hailong, 2J

Wang, T., 2C

Watts, Steve, $1 \mathrm{H}$

Weber, W., 13

Wegrowe, J.-E., 10

Wehrmann, Isabel, 23

Wen, Shuangchun, 01

Wenk, Paul, 23

Wessels, Bruce W., $1 \mathrm{~J}$

Wheeler, Dustin D., 00

Wiegand, J., 2R

Wolf, Georg, $1 \mathrm{H}$

Wolf, Michael, 07

Wood, R., ON

Wu, Yizheng, OT

Wulfhekel, W., 13 
$\mathrm{XU}, \mathrm{K} ., 1 \mathrm{~B}$

Yang, C. S., OL

Yang, Fengyuan, 2J

Zhang, Tiantian, $\mathrm{OA}$

Zhang, Xinhui, OT

Zhao, Jianhua, OT

Zhou, Xinxing, Ol

Zutic, I., OL

Proc. of SPIE Vol. $9167916701-9$

Downloaded From: https://www.spiedigitallibrary.org/conference-proceedings-of-spie on 26 Apr 2023 Terms of Use: https://www.spiedigitallibrary.org/terms-of-use 
Proc. of SPIE Vol. 9167 916701-10

Downloaded From: https://www.spiedigitallibrary.org/conference-proceedings-of-spie on 26 Apr 2023 Terms of Use: https://www.spiedigitallibrary.org/terms-of-use 


\section{Conference Committee}

Symposium Chairs

Satoshi Kawata, Osaka University (Japan)

Manijeh Razeghi, Northwestern University (United States)

Symposium Co-chairs

David L. Andrews, University of East Anglia Norwich (United Kingdom) James G. Grote, Air Force Research Laboratory (United States)

\section{Conference Chairs}

Henri-Jean Drouhin, Ecole Polytechnique (France) Jean-Eric Wegrowe, Ecole Polytechnique (France)

Manijeh Razeghi, Northwestern University (United States)

\section{Conference Program Committee}

Franco Ciccacci, Politecnico di Milano (Italy)

Russell P. Cowburn, University of Cambridge (United Kingdom)

Scott A. Crooker, Los Alamos National Laboratory (United States)

Vincent Cros, Unité Mixte de Physique CNRS/Thales (France)

Hanan Dery, University of Rochester (United States)

Rogério de Sousa, University of Victoria (Canada)

Michel I. Dyakonov, Université Montpellier 2 (France)

Michael E. Flatté, The University of lowa (United States)

Jean-Marie George, Unité Mixte de Physique CNRS/Thales (France)

Erez Hasman, Technion-Israel Institute of Technology (Israel)

Henri Jaffrès, Unité Mixte de Physique CNRS/Thales (France)

Tomás Jungwirth, Institute of Physics of the ASCR, v.v.i.

(Czech Republic)

Giti A. Khodaparast, Virginia Polytechnic Institute and State University (United States)

Mathias Klaui, Universität Konstanz (Germany)

Xavier Marie, INSA - Université de Toulouse (France)

Laurens W. Molenkamp, Julius-Maximilians-Universität Würzburg

(Germany)

Hiro Munekata, Tokyo Institute of Technology (Japan)

Yoshichika Otani, The University of Tokyo (Japan)

Dafiné Ravelosona, Institut d'Électronique Fondamentale (France)

Georg Schmidt, Martin-Luther- Universität Halle-Wittenberg (Germany)

Jing Shi, University of California, Riverside (United States) 
Luc Thomas, Headway Technology (United States)

Evgeny Tsymbal, University of Nebraska-Lincoln (United States)

Olaf M. J. van 't Erve, U.S. Naval Research Laboratory (United States) Joerg Wunderlich, Hitachi Cambridge Laboratory (United Kingdom) Igor Zutic, University at Buffalo (United States)

\section{Session Chairs}

la Spin Laser

Henri Jaffrès, Unité Mixte de Physique CNRS/Thales (France)

1b Spin Coherence in Quantum Dots

Jean J. Heremans, Virginia Polytechnic Institute and State University (United States)

2a Optical Pumping I

Takashi Kuroda, National Institute for Materials Science (Japan)

2b Spin Coherence II

Kimberley C. Hall, Dalhousie University (Canada)

3a Spin Photonics

Sophia E. Hayes, Washington University in St. Louis (United States)

3b Spin Coherence and Magnetic Polarons

Benedict Murdin, University of Surrey (United Kingdom)

4a Optical Pumping II

Christian Rinaldi, Politecnico di Milano (Italy)

4b Multiferroics, Half Metals, and Oxides

Vlad S. Pribiag, Kavli Institute of Nanoscience Delft (Netherlands)

5 Skyrmions

Wolfgang Weber, Institut de Physique et Chimie des Matériaux de Strasbourg (France)

6 Helical Order and Organics

Luiz Sampaio Lima, Centro Brasileiro de Pesquisas Físicas (Brazil)

7 Magnetooptics and Landé Factor

Christopher J. Stanton, University of Florida (United States)

8 Magnetic RAM I

Luc Thomas, Headway Technologies, Inc. (United States) 
9 Magnetic RAM II

Hideo Ohno, Tohoku University (Japan)

10 Magnetic RAM and Logic Devices

Hiroaki Yoda, Toshiba Corporation (Japan)

11 Spin Caloric Transport I

Jean-Eric Wegrowe, Ecole Polytechnique (France)

12 Spin Caloric Transport II

Sadamichi Maekawa, Japan Atomic Energy Agency (Japan)

13 Spin Transfer and Spin-Orbit Interaction

Sadamichi Maekawa, Japan Atomic Energy Agency (Japan)

14 Spin Transfer and Domain Walls

Ingrid Mertig, Martin-Luther Universität Halle-Wittenberg (Germany)

15a Spin-Orbit Coupling

Giti A. Khodaparast, Virginia Polytechnic Institute and State University (United States)

15b Optical and Electrical Control

Ewelina Hankiewicz, Julius-Maximilians- Universität Würzburg (Germany)

16a Spin Pumping I

Yuichiro Ando, Osaka University (Japan)

16b Ultrafast Optical Control and Topological Insulators I

Peter Stano, RIKEN (Japan)

17a Spin Pumping II

Antonio Azevedo, Universidade Federal de Pernambuco (Brazil)

17b Topological Insulators and Majorana Fermions

Fabio Pezzoli, Università degli Studi di Milano-Bicocca (Italy)

18a Spin Pumping and Spin Noise

Olivier Klein, Commissariat à l'Énergie Atomique (France)

18b Graphene and Chalcogenides

Connie H. Li, U.S. Naval Research Laboratory (United States) 
Proc. of SPIE Vol. 9167 916701-14

Downloaded From: https://www.spiedigitallibrary.org/conference-proceedings-of-spie on 26 Apr 2023 Terms of Use: https://www.spiedigitallibrary.org/terms-of-use 


\section{Introduction}

The seventh edition of the Spintronics symposium of the SPIE conference gathered more than one hundred speakers in San Diego from Sunday to Thursday, 17-21 August 2014.

In line with the previous editions, the Spintronics symposium held in the framework of the Optics+Photonics conference covered most of the hot topics in Spintronics. The conference was also an invaluable opportunity for informal and extremely stimulating discussions between experts and networking in a friendly atmosphere, witnessing for the dynamism of our field of research. These proceedings do not include a full overview of the presentations, but they report a significant part (about 33\%) of important results presented at the meeting. The symposium concerns fundamental results in experimental and theoretical physics, and also technological developments. During the last year, we have felt that the MRAM technology is really coming to market, and may have a strong impact on the future of data storage and processing; therefore, we had three focused sessions (8-11) with the participation of key industrial partners, and a key-note opening by Hideo Ohno (Tohoku University). The state of the art in domain wall manipulation and application was presented by S. S. P. Parkin in a keynote lecture. Besides, the program shows the growing importance of the studies and developments about optical manipulation and detection of spins, with a whole session (1) devoted to spin laser, a session on spin photonics (3A), a session based on magnetooptics (7), and two sessions related to optical pumping (2A and $4 \mathrm{~A})$.

The symposium was divided into 26 oral sessions plus one poster session that covered: Low-dimensional systems (sessions $2 B$ and $3 B$ ), multiferroics, half-metals, oxides, and skyrmions (sessions $4 \mathrm{~B}$ and 5), helical order and organic semiconductors (session 6), domain walls (session 14), spin caloric transport (sessions 11 and 12), spin transfer and spin-orbit interaction (sessions 13 and 15A), optical and electrical control (session 15B), spin pumping (sessions 16A, 17A, and 18A), topological insulators and Majorana fermions (sessions $16 \mathrm{~B}$ and 17B), and graphene and chalcogenides (session 18B).

If new fields are emerging (Majorana fermions and helical order), the traditional topics of spintronics remain very active (spin injection, spin dynamics, spin transfer, spin Hanle effect, spin-Hall effects, spin pumping etc). Moreover, this 7 th edition of the symposium has shown that there are still exciting debates related to Spin Caloritronics. This topic triggered many open discussions on the possible interpretation of experimental data.

Finally, we are grateful to SPIE, to the Program Committee members who did tremendous work, and to all speakers and authors for their active participation: they have made this conference a great success. 
Proc. of SPIE Vol. 9167 916701-16

Downloaded From: https://www.spiedigitallibrary.org/conference-proceedings-of-spie on 26 Apr 2023 Terms of Use: https://www.spiedigitallibrary.org/terms-of-use 